\title{
ANALYZING THE RELATIONSHIP BETWEEN BATCH SIZING AND BULLWHIP EFFECT IN TWO-TIER SUPPLY CHAIN: A CASE STUDY OF SELECTED PAKISTANI RICE FIRMS
}

\author{
ShoaibYousaf \\ International Islamic University, Islamabad, Pakistan \\ Matloub Hussain \\ Abu Dhabi University, P.O Box 59911, Abu Dhabi, UAE
}

\begin{abstract}
The purpose of this research is to investigate the bullwhip effect in two tier supply chain. Simulation has been used as a methodology to analyse the impact of batching on bullwhip in rice industry of Pakistan. Two cases of the rice industry have been chosen as a sample. The contribution of this research is two-fold. Firstly, the current research is an extension of a study by Hussain and Drake (2011) that analyses the relationship between batch size and bullwhip effect as non-monotonic, whereby the size of the remainder of quotient determines the value of bullwhip effect. Secondly, the batch size has less frequently been studied in the context of bullwhip effect; hence the researcher has extended strength to the existing supply chain model. It has been found that the relationship between batch size and demand amplification is non linear. It cannot be said that reducing the batch size will minimize the bullwhip effect. Batch size larger than average demand does not result in bullwhip effect. In other words, variance of the order quantity is smaller than the variance of demand, which leads to anti-bullwhip or dewhips effect. This study will help the practitioners and supply chain managers to control the bullwhip produced by batching effect across multi-echelon supply chains. However, this study has been based on two tier supply chain while in reality supply chain has got many tiers. Hence, this study can be extended across more than two tier supply chains.
\end{abstract}

Keywords: Supply Chain Dynamics, Bullwhip Effect, Batching, Simulation, Rice Industry.

JEL Code: L11

\section{INTRODUCTION}

One of the most significant supply chain research problems, that have drawn much attention for more than four decades, is the phenomenon well-known as the "Bullwhip Effect" i.e. a condition where demand distortion magnifies, as one moves up in the supply chain. Forrester (1961) was the pioneer, who explored demand amplification in supply chain dynamics, also called "Forrester Effect" or the "Law of Industrial Dynamics" at the Massachusetts Institute of Technology. This attracted many researchers and triggered a curiosity among them to understand its causes. Forrester identified that demand amplification is due to system dynamics and can be tackled by reducing delays in the supply chain. Then, Sterman (1989) explored the bullwhip effect in a "Beer Distribution Game" and concluded that this phenomenon occurs due to "irrational behaviour" of supply chain players. After that, Lee et al., (1997a, b) identified the causes of bullwhip effect in upstream nodes in the supply chain players. Five causes of bullwhip are demand signal processing/demand forecasting, order batching, price fluctuation, rationing and shortage gaming (Lee et al., 1997a, b) and lead time (Chen et al., 2000; de Souza et al., 
2000). Disney and Lambrecht (2008) wrote a textbook to identify the causes and provide some remedies. In past the researchers tried hard to eradicate the menace of bullwhip effect. However, this problem is persistent in the supply chain management, and it is a source of continuous perturbance for the industrialists.

Batch sizing is one of the most irritating problems caused by the bullwhip effect identified by (Lee et al. 1997a, b; Riddalls and Bennett 2001). It is also termed lot sizing. It refers to the phenomenon of placing orders to upstream tiers in batches. The main reason for a company ordering in batches is that it may prove to be less costly because of transportation costs or the company might receive a discount if a large quantity is ordered in one period (Burbridge, 1991). In a traditional perspective, to determine the optimal batch size, industrialists have to analyze the trade-off between ordering costs, storage and holding costs, and stock out costs, which is generally well-known as Economic Order Quantity (EOQ) (Lee et al. 1997b). Order batching refers to Economic Batch Quantity (EBQ) and Economic Production Quantity (EPQ) for a company ordering a large quantity of products in one week and not ordering any for many weeks where it is economically conducive for a company to produce large batches which can reduce the number of facility set-up and enhance manufacturing efficiency.

The present paper focuses on the impact of batch sizing on bullwhip effect with real time data. For this current paper the primary data has been collected from the rice industry of Pakistan. This paper fills a missing piece in the landscape of batching on the bullwhip effect for supply chain applications in academia. A few studies have been conducted in the context of supply chain management with reference to Pakistan. It has been noticed that rice industrialists are facing dire problems related to supplying their products to other chain members in the supply chain. Unfortunately; no model has been used in the rice industry of Pakistan so far. This study is filling the gap in the existing literature since no detailed investigation has been carried out to explore the impact of batch size on the bullwhip effect in the two-tier supply chain. No real time data has been utilized by the past researchers. The supply chain model Automatic Pipeline Inventory and Order Based Production Control System (APIOBPCS) has been implemented for the first time with special reference to Pakistan.

The rest of paper is split in four sections. Section 2 presents research methodology. In section 3 , the model is presented. Section 4 summarizes the impact of batching on bullwhip effect, and conclusion is presented in section 5 .

\section{METHODOLOGY}

The case study approach has been selected as it is an apt method to describe and explore a new phenomenon. Keeping in view the dynamics of the issues, this research has applied the continuous simulation modelling technique and the case study research as a research methodology. To simulate the APIOBPCS model, "What-If" analysis has been applied in this research. Computer software Microsoft Excel 2007 is used for simulation techniques.

\section{TWO-TIER SUPPLY CHAIN MODEL}

Figure 1 shows the simulation model of two-tier supply chain consisting of one manufacturer and one distributor. The APIOBPCS model expressed by John et al. (1994) as "Lets the 
production targets be equal to the sum of an exponentially smoothed demand (over Ta units of time) plus a fraction (1/Ti) of the inventory error, plus a fraction (1/ Tw) of the work in progress (WIP) error. The model comprises four parameters (each-tier) that are Ta, Ti, Tw, and Tp. Ta is the parameter that expresses how quickly demand is tracked in the exponential smoothing forecasting technique, while $\mathrm{Ti}$ suggests that the difference between the actual and desired/target inventory levels is added to the production/distribution order rate (ORATE). Tw describes how much of the discrepancy between the actual work-in-process (WIP) and desired/target WIP levels should be added to the production/distribution ORATE. Tp describes the actual pipeline delay between an order being placed and its receipt into stock - see Figure 1.

In summary

$$
\begin{aligned}
& S A L E S=\text { Is the actual end customer demand } \\
& \text { SALES }=\text { ORATE } \\
& S S A L E S=S S A L E S+(S A L E S-S A L E S)^{*} 1 / T a \\
& \text { ORATE }=\text { SSALES }+E I N V / T i+E W I P / T a \\
& C O M R A T E=O R A T E \\
& A I N V=A I N V+C O M R A T E-S A L E S \\
& D I N V=S A L E S \\
& E I N V=D I N V-A I N V \\
& D W I P=T P X S S A L E S \\
& E W I P=D W I P-W I P
\end{aligned}
$$

In the current research the supply chain APIOBPCS model has been extended by introducing batch ordering. Batching is introduced by the ROUND function in the Microsoft Excel program. The round function rounds values up to the next integer value. So to convent an ORATE to batches of size (BS), the following formula is applied:

Number of Batches $=$ ROUND (ORATE / BS)

And the new ORATE is then:

Batched ORATE $=$ Number of batches $x$ BS

\section{MEASURING THE BULLWHIP EFFECT}

Past researchers have applied different statistical equations to calculate the variance, like Reinder and Trcka (2004) used to calculate the total bullwhip effect through coefficient of variance of the manufacturer and divided it on the coefficient of variance of the consumer demand. Hussain et al. (2007) used coefficient of orders placed and divided it on the orders received. In the current research, the following equation has been used to calculate the bullwhip effect. This equation is mostly used in literature (e.g., Muramatsu et al. 1985; Disney and Towill, 2003b; Bottani and Montanari, 2010; Hussain and Drake, 2011). 
Bullwhip $=\sigma^{2}$ orders $/ \sigma^{2}$ demand

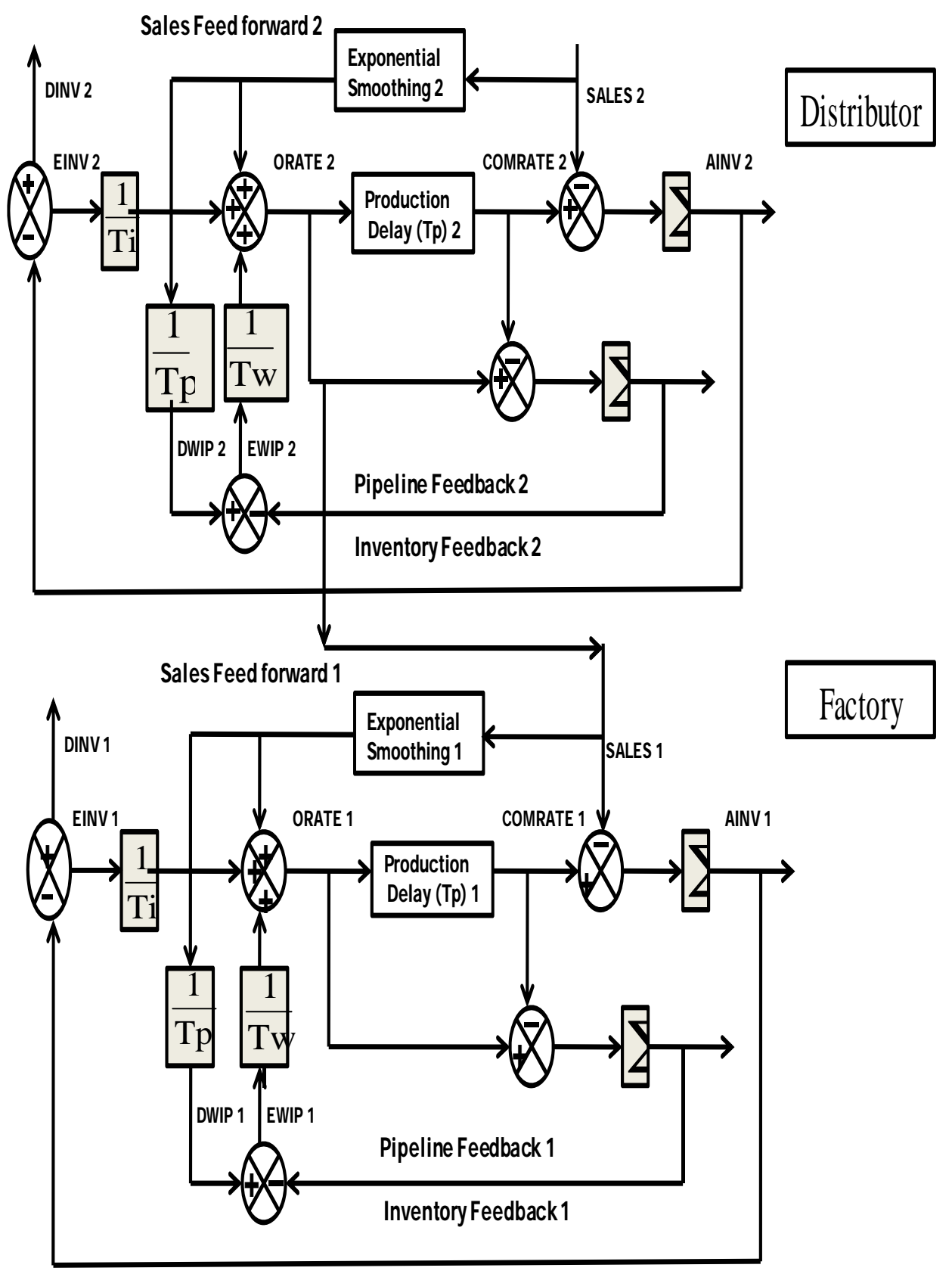

Figure 1: Block Diagram of Two-Tier APIOBPCS Model. 


\section{ANALYSIS OF THE IMPACT OF BATCHING ON BULLWHIP EFFECT}

In this research, two case studies have been selected from the rice industry of Pakistan. The data for the study is collected from the demand and sales sheets of a group of four large rice manufacturers and their distributors (two-each) from the districts of Lahore and Islamabad, Pakistan. Since this is a case study research, therefore, the data from four firms is considered sufficient to examine the impact of different batch size on bullwhip effect for the selected firms.

In this study, the APIOBPCS model has been adopted from John et al. (1994). The value of parameters from the model applied in this research are $\mathrm{Tp}=\mathrm{Tw}=6$ and $\mathrm{Ta}=2 \mathrm{Tp}=12$, i.e. $\mathrm{a}$ good set of values in accordance with the findings of the Mason-Jones et al. (1997) and as well as used by Wilson (2007). The detailed investigation on the impact of batching on the bullwhip effect has been tested through different scenarios' of simulation modelling technique. Simulation was carried out 520 times within 100 weeks, both from the manufacturers' and distributors' perspective. The main purpose of conducting the study is two-fold. Firstly, is to find out the optimum level of batch sizes, and secondly to make easy for the supply chain managers and operation managers for mitigating the bullwhip effect. For these purposes, the batch sizes of manufacturers and their distributors have been selected as practically used, i.e. $1 \mathrm{kilogram}(\mathrm{kg}), 2 \mathrm{~kg}, 5 \mathrm{~kg}, 10 \mathrm{~kg}, 20 \mathrm{~kg}, 30 \mathrm{~kg}$, and $40 \mathrm{~kg}$ for the distributors and $5 \mathrm{~kg}, 10 \mathrm{~kg}, 20 \mathrm{~kg}$, $30 \mathrm{~kg}$, and $40 \mathrm{~kg}$ for manufacturers.

By using simulation modelling technique on data analysis, it has been found that when the batch sizes of manufacturers are selected $5 \mathrm{~kg}, 10 \mathrm{~kg}$, and $30 \mathrm{~kg}$, the value of variance of orders is high. On the contrary, when the batch size of the manufacturer is selected $40 \mathrm{~kg}$, the value of variance of orders lessens. Likewise, when compared the values of variance of the batch sizes from the manufacturers' perspective, the $40 \mathrm{~kg}$ batch size obtains an optimal value of variance, mitigating the bullwhip effect. However, from the distributors' point of view, the variance of orders cannot be minimized when the batch size is reduced. For the first distributor, the optimal level of variance can be achieved when the batch size is $20 \mathrm{~kg}$ as compared to batch sizes of $1 \mathrm{~kg}, 2 \mathrm{~kg}$, $5 \mathrm{~kg}$, and $10 \mathrm{~kg}$. Same is the factual position of the second distributor whose optimal value of variance is also achieved when the batch size is $20 \mathrm{~kg}$.

Table 1: Variance Values of Tier1 and Tier 2 in FIRST CASE

\begin{tabular}{lllll}
\hline $\begin{array}{l}\text { Sr. } \\
\text { No }\end{array}$ & Weeks & $\begin{array}{l}\text { Batch Sizes (Distributor, } \\
\text { Manufacturer) }\end{array}$ & $\begin{array}{l}\text { Tier 1 (Variance } \\
\text { Value of } \\
\text { Distributor) }\end{array}$ & $\begin{array}{l}\text { Tier 2 (Variance } \\
\text { Value of } \\
\text { Manufacturer) }\end{array}$ \\
\hline 1 & 1 to 100 & $1 \mathrm{Kg}, 5 \mathrm{Kg}$ & $946,955.01$ & $159,330,822.55$ \\
2 & 1 to 100 & $2 \mathrm{Kg}, 10 \mathrm{Kg}$ & $946,913.23$ & $159,342,163.02$ \\
3 & 1 to 100 & $5 \mathrm{Kg}, 20 \mathrm{Kg}$ & $947,229.48$ & $159,324,694.95$ \\
4 & 1 to 100 & $10 \mathrm{Kg}, 30 \mathrm{Kg}$ & $946,250.46$ & $159,332,056.00$ \\
5 & 1 to 100 & $20 \mathrm{Kg}, 40 \mathrm{Kg}$ & $946,145.45$ & $159,298,045.90$ \\
6 & 1 to 100 & 30Kg, 40Kg & $950,400.00$ & $159,298,045.90$ \\
7 & 1 to 100 & $40 \mathrm{Kg}, 40 \mathrm{Kg}$ & $947,203.88$ & $159,298,045.90$ \\
8 & 1 to 100 & $20 \mathrm{Kg}, 40 \mathrm{Kg}$ & $946,145.45$ & $159,298,045.90$ \\
\hline
\end{tabular}


Table 2: Variance Values of Tier 1 and Tier 2 in SECOND CASE

\begin{tabular}{lllll}
\hline $\begin{array}{l}\text { Sr. } \\
\text { No }\end{array}$ & Weeks & $\begin{array}{l}\text { Batch Sizes (Distributor, } \\
\text { Manufacturer) }\end{array}$ & $\begin{array}{l}\text { Tier 1 (Variance } \\
\text { Value of } \\
\text { Distributor) }\end{array}$ & $\begin{array}{l}\text { Tier 2 (Variance } \\
\text { Value of } \\
\text { Manufacturer) }\end{array}$ \\
\hline 1 & 1 to 100 & $1 \mathrm{Kg}, 5 \mathrm{Kg}$ & $653,598.85$ & $479,816,295.14$ \\
2 & 1 to 100 & $2 \mathrm{Kg}, 10 \mathrm{Kg}$ & $653,468.02$ & $479,846,164.15$ \\
3 & 1 to 100 & $5 \mathrm{Kg}, 20 \mathrm{Kg}$ & $653,914.91$ & $479,819,397.33$ \\
4 & 1 to 100 & $10 \mathrm{Kg}, 30 \mathrm{Kg}$ & $653,620.31$ & $479,886,697.73$ \\
5 & 1 to 100 & $20 \mathrm{Kg}, 40 \mathrm{Kg}$ & $652,599.76$ & $479,782,944.81$ \\
6 & 1 to 100 & $30 \mathrm{Kg}, 40 \mathrm{Kg}$ & $654,751.27$ & $479,782,944.81$ \\
7 & 1 to 100 & $40 \mathrm{Kg}, 40 \mathrm{Kg}$ & $654,773.49$ & $479,782,944.81$ \\
8 & 1 to 100 & $20 \mathrm{Kg}, 40 \mathrm{Kg}$ & $652,599.76$ & $479,782,944.81$ \\
\hline
\end{tabular}

The results of this research have confirmed that a large batch size than the average demand, results in no bullwhip effect or the variance of the order quantity is smaller than the variance of demand, which leads to anti-bullwhip or de-whips effect. A de-whip effect means that the production planning phase at the manufacturer's level becomes easier and more stable. The manufacturer prefers to smooth production and a smooth ordering pattern from the retailer. The bullwhip effect increases the variance in orders and destabilizes the production planning phase at the manufacturer's level. When the variance of the order quantity is smaller than the variance of the demand (de-whip effect), the production manager can plan efficient production schedule and minimize the production cost.

This research provides a great deal of managerial implications for making effective decisions. The production and inventory holding costs play a pivotal role in every organization to maximize its profits. The strategic management of an organization mainly focuses on this aspect, irrespective of the fact that it is doing a small business or a large one. Batch sizing is also a one of the factors that increases production and inventory holding costs. Due to batch sizing, the production and inventory holding costs of their products increases. In this situation, the industrialists are unable to handle their stock that leads to out of stock, and sometimes extra stock is accumulated. The operational managers do not know how to tackle these problems. These problems can be controlled and minimized by utilizing the proper batch sizes. By employing the proper batch sizes, they can gain competitive advantage over their competitors by grabbing the market share through controlling the batch sizes. Moreover, they can minimize the cost of their labour, inventory and operations.

By examining this trend, the production managers are able to forecast high amplification in advance and can better pre-plan to change the batch size to minimize this amplification. This is quite logical as the batch size increases, the managerial cost of production minimizes, so it is more convenient to take the advantage of this temporary low production cost and a small increase in production can be accommodated by increasing the batch size to integer multiple of the average demand without requiring a whole new batch.

By looking at the graph of bullwhip effect caused by batch size, the operations managers can substantially minimize the inventory holding cost, switching over cost and backlog cost by 
cautiously selecting the batch size without complex mathematical calculations. When the upstream tiers of the supply chain are not working with the batching constraint in their order rates, changing the batch size of the distributor does not have any impact on the demand amplification of the factory.

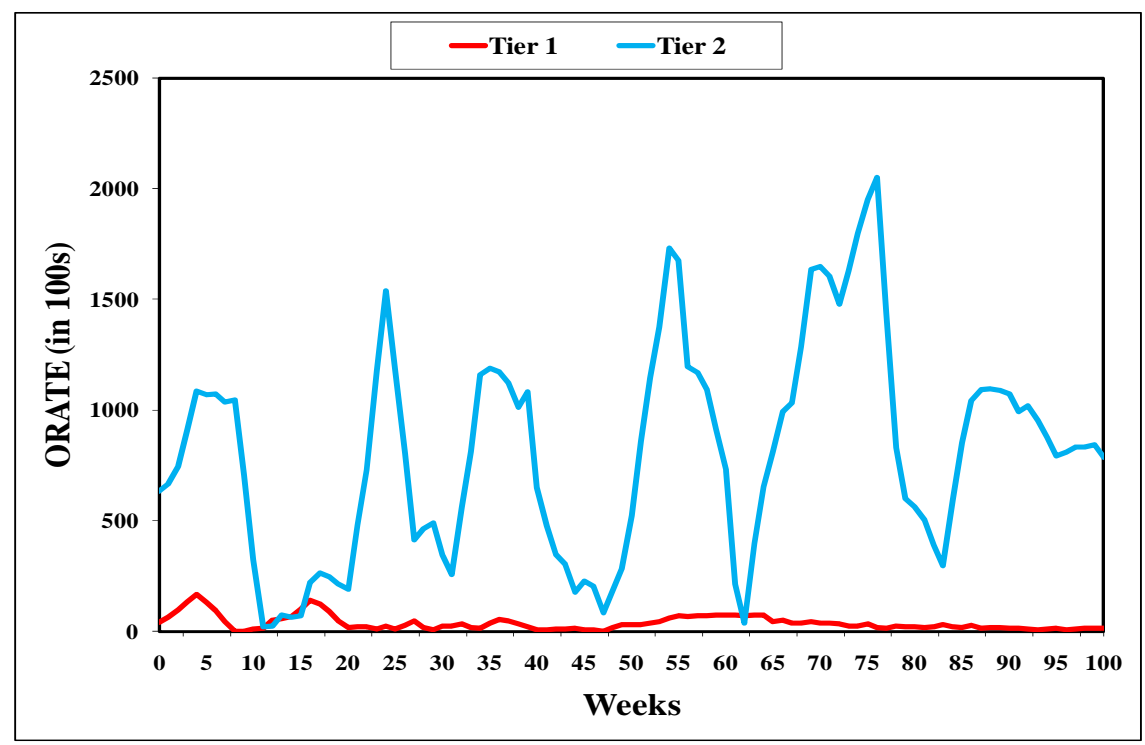

Figure 2: Impact of 20kg \& 40Kg Batch Sizes on Bullwhip Effect in FIRST CASE

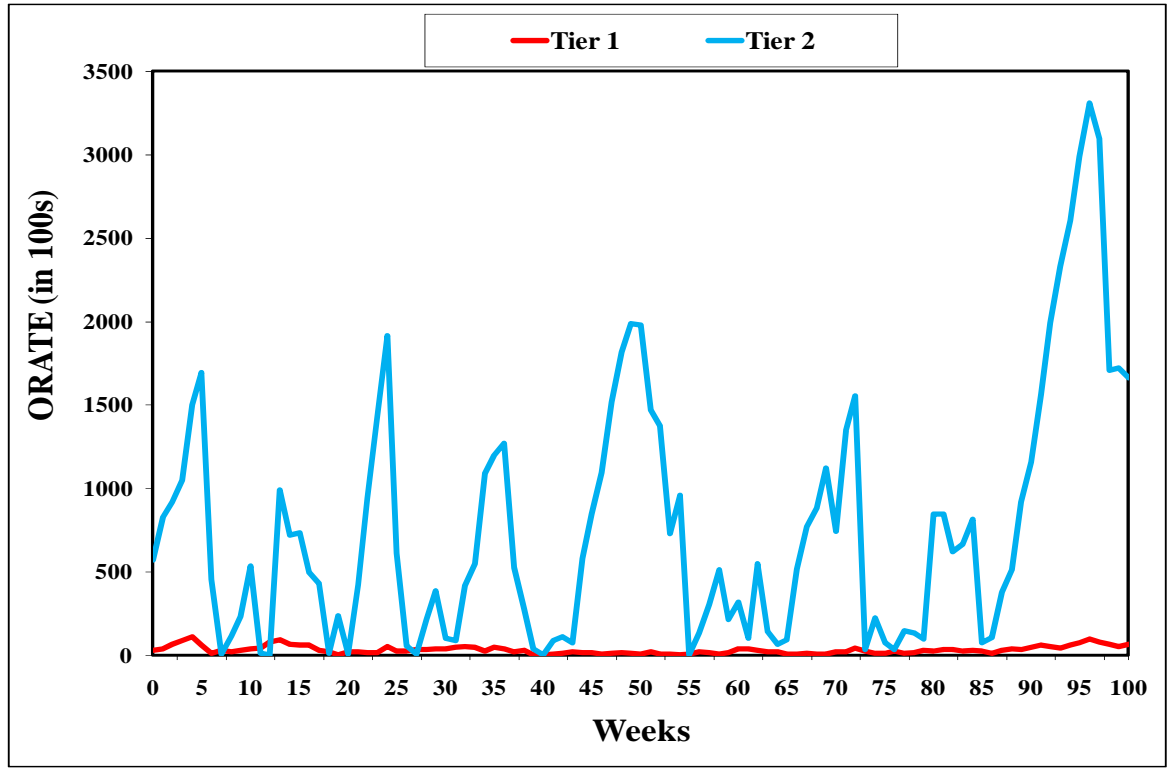

Figure 3: Impact of 20Kg \& 40Kg Batch size on Bullwhip Effect in SECOND CASE 


\section{CONCLUSION}

The original contribution of this research is two-fold. Firstly, it provides an empirical testing of a conceptual study by Hussain and Drake (2011), which analysed the relationship between batch size and the bullwhip effect as non-monotonic and that the size of remainder of quotient determines the value of bullwhip effect. Thus far, there has been no empirical evidence available related to the impact of batch sizing on the bullwhip effect in the existing literature. Secondly, it provides the extension of APIOBPCS supply chain model by incorporating batch sizing.

This research supports the research conducted by Hussain and Drake (2011) in a way that the smallest batch size does not lead to lower amplification. It is also conformity with the findings of (Riddalls and Bennett 2001; Potter and Disney 2006). However, it challenges Burbridge, (1981), who espoused that the smallest batch size leads to lower amplification. Mehra et al. (2006) also found that through smaller batch sizes in a process industry, demand amplification lessens as compared to larger batch sizes. Hejazi and Hilmola (2006) identified that splitting bulky incoming orders into small production batches is the proficient scheme to fight against the bullwhip effect.

Although, batch sizing is one of the most enigmatic issues for the manufacturers since there are a number of good reasons to make them larger and other good reasons to make them smaller batch sizes. To avoid a war, organizations want to identify whether they should make either larger or smaller batch sizes. This study vehemently recommends that: larger batch sizes are more beneficial for gaining profits. This will also help them to avoid delay in supplying to their chains. To this end, larger batch sizes will be the desired strategy as they will create minimum bullwhip effect as compared to the small batch sizes.

As this research focuses only on the rice industry, the findings are apparently valid for this industry and may not be generalized for all the industries. However, there is a need to investigate this issue in some other case studies in order to validate the findings. While the two case studies have been conducted during this research, there is a need to carry out more case studies to explore the impacts and validate the results of the present study. 


\section{REFERENCES}

Bottani, E. \& Montanari, R. 2010 'Supply chain design: Guidelines from a simulation approach', Discrete Event Simulations, pp. 1-16. Doi: 10.5772/9896.

Burbridge, J. L. 1981 'The new approach to production', Production Engineer, vol. 40, no. 12, pp. 769-784.

Burbridge, J. L. 1991 'Period batch control (PBC) with GT-the way forward from MRP', BPCIS Annual Conference, Birmingham.

Chen, F., Drezner, Z. \& Simchi-Levi,D. 2000b 'Quantifying the Bullwhip Effect in a simple supply chain: the impact of forecasting, lead times, and information', Management Sciences, vol. 46, no. 3, pp. 436-443.

de Souza, R Chaoyang, L \& Zice, S 2000, 'Supply Chain dynamics and optimization', Integrated Manufacturing System, vol. 11, no. 5, pp. 348-364.

Disney, S. M. \& Towill, D. R. 2003b 'Vendor-managed inventory and bullwhip reduction in a two-level supply chain', International Journal of Operations \& Production Management, vol. 23, no. 6, pp. 625-651.

Disney, S. M. \& Lambrecht, M. R. 2008 'On replenishment Rules, Forecasting and the Bullwhip Effect in Supply Chains', Foundations and Trends ${ }^{\circledR}$ in Technology, Information and Operations Management, vol. 2, no.1, pp. 1-80.

Forrester, J. W. 1961 'Industrial Dynamics', MIT Press and John Wiley \& Sons, Inc., New York.

Hejazi, A. \& Hilmola, O-P. 2006 'Manufacturing lot sizing as source of bullwhip effect: a case study of electronic and furniture supply chains', International Journal of Services and Operations Management, vol. 2, no. 3, pp. 237-255.

Hussain, M. \& Drake, P. R. 2011 'Analysis of the bullwhip effect with order batching in multiechelon supply chains', International Journal of Physical Distribution \& Logistics Management, vol. 41, no. 10, pp. 972-990.

Hussain, M., Drake, P. R., \& Lee, D. M 2007 'Quantifying the impact of a supply chain's design parameters on the bullwhip effect', 7th Global Conference on Business \& Economics. Rome, Italy.

John, S Naim, MM \& Towill, DR 1994 'Dynamic analysis of a WIP compensated decision support system', International Journal of Manufacturing System Design, vol. 1, no. 4, pp. 283297.

Lee, HL Phadmanabhan, V \& Whang, S 1997a 'Information distortion in the supply chain: The Bullwhip Effect', Management Sciences, vol. 43, no. 4, pp. 546-559.

Lee, HL Phadmanabhan, V \& Whang, S 1997b 'The bullwhip effect in supply chains', Sloan Management Review, vol. 38, no. 3, pp. 93-102.

Mason-Jones, R Naim, MM \& Towill, DR 1997 'The impact of pipeline control on supply chain dynamics', The International Journal of Logistics Management, vol. 8, no. 2, pp. 47-61. 
Mehra, S Inam, R A \& Tuite, G 2006 'A simulation-based comparison of batch sizes in a continuous process industry', Production Planning \& Control, vol. 17, no. 1, pp. 54-66.

Muramatsu, R Ishii, K \& Katsuhtko T 1985 'Some ways to increase flexibility in manufacturing systems', International Journal of Production Research, vol. 23, no. 4, pp. 691-703.

Potter, A \& Disney, SM 2006, 'Bullwhip and batching: an exploration', International Journal of Production Economics, vol. 104, no. 4, pp. 408-418.

Reinder, G. \& Trcka, M. 2004 'Customized supply chain design: problems and alternatives for a production company in the food industry, a simulation based analysis', International Journal of Production Economics, vol. 89, pp. 217-229.

Riddalls, C. E. \& Bennett, S. 2001 'The optimal control of batched production and its effect on demand amplification', International Journal of Production Economics, vol.72, pp. 159-168.

Sterman, J. 1989 'Modeling managerial behavior: misperception of feedback in a dynamic decision making experiment', Management Sciences, vol. 35, no. 3, pp. 321-339.

Wilson, C. M. 2007 'The impact of transportation disruptions on supply chain performance', Transportation Research Part E: Logistic and Transportation Review, vol. 43, no. 4, pp. 295320. 